\title{
Responsiveness of the Indian Tax System: A Time Series Analysis from 1990 to 2010
}

\author{
Debasis Patnaik ${ }^{1}$ \\ Annie Pillai ${ }^{2}$ (D) \\ Asst Prof, Department of Economics, BITS Pilani K K Birla Goa Campus, India \\ ${ }^{\circ} \mathrm{MS}$ Economics, Department of Economics. BITS Pilani K K Birla Goa Campus, India
}

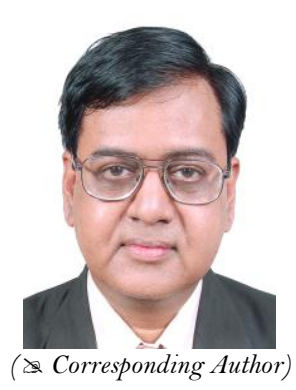

\section{Abstract}

The post reform period in Indian fiscal system needed to assess the impact of reforms as regards tax buoyancy and elasticity of Indian tax system in pre GST exercise. This paper studies the variation in buoyancy of the following taxes: Corporation Tax, Income Tax, Customs tax, Union Excise Duty. It also attempts to study the elasticities of the above mentioned taxes by eliminating the impact of discretionary changes.

Keywords: Tax elasticity, Indian tax system, Time series, GDP, Tax revenue, Tax buoyancy.

Citation | Debasis Patnaik; Ms Annie Pillai (2017). Responsiveness of the Indian Tax System: A Time Series Analysis from 1990 to 2010. Economy, 4(1): 1-6.

History:

Received: 13 July 2016

Revised: 8 May 2017

Accepted: 24 May 2017

Published: 22 June 2017

Licensed: This work is licensed under a Creative Commons

Attribution 3.0 License (cc) Er

Publisher: Asian Online Journal Publishing Group
Contribution/Acknowledgement: Both authors contributed to the conception and design of the study.

Funding: This study received no specific financial support.

Competing Interests: The authors declare that they have no conflict of interests.

Transparency: The authors confirm that the manuscript is an honest, accurate, and transparent account of the study was reported; that no vital features of the study have been omitted; and that any discrepancies from the study as planned have been explained.

Ethical: This study follows all ethical practices during writing.

\section{Contents}

1. Introduction

2. Literature Reviews...

2.6. Objective.

3. Methodology

4. Data and Results

5. Conclusion

Appendix

References.

Bibliography. 


\section{Introduction}

India has a well-developed tax structure with clearly demarcated authority between Central and State Governments and local bodies. Central Government levies taxes on income (except tax on agricultural income, which the State Governments can levy), customs duties, central excise and service tax.

Indian taxation system has undergone tremendous reforms during the last 2 decades. The Tax Reform Committee was set up in 1990 to rationalize the tax system in India. Various reforms were brought into the system from the recommendations of this committee. Thus it is important to study how effective these reforms have been and hence the period of study chosen is from 1991 to 2010 . The tax rates have been rationalized and tax laws have been simplified resulting in better compliance, ease of tax payment and better enforcement. The process of rationalization of tax administration is ongoing in India. It is important to analyze the responsiveness of tax revenue to aid the policy makers in this process. To measure the tax sensitivity, tax elasticity and tax buoyancy are used widely.

Tax elasticity is change in the tax revenue due to a change in GDP (or relevant GDP component). Tax buoyancy is change in tax revenue due to a change in tax rates, bases, rules, administrative efficiency, etc. (discretionary changes). Thus, we see that tax buoyancy measures total change in tax revenues i.e. including effect of discretionary measures and GDP changes.

It is vital to study both effects as each of these corresponds to increase in the tax revenue due to different factors. Tax buoyancy is effect of increase in the tax base along with the impact of tax reforms whereas tax elasticity excludes the effect of discretionary tax measures focusing only on the impact of increase in the national income.

\section{Literature Reviews}

\subsection{Elasticity and Buoyancy of Major Taxes in Pakistan}

Fauzia (2001) estimates the elasticity and buoyancy for four major tax revenue sources of Pakistan - direct tax, sales tax, customs duties and excise duties - for the period 1981-2001 using the Chain Indexing Technique. Elasticity is calculated by first removing the effects of discretionary changes on the tax revenues and then a twostep regression analysis which gives the responsiveness of the tax base to the GDP and tax revenue to tax base. The paper finds that the elasticity of direct and sales taxes have a relatively higher elasticity as compared to customs and excise duties, which appear to be very rigid. Also, it was found that the discretionary measures were found to have a positive effect on the tax structure, improving the elasticities of all the taxes.

\subsection{The Trends and Responsiveness of Personal Income Tax in India}

Ankita (2009) presented in the Fourth Annual International Conference on Public Policy and Management, analyses the responsiveness of personal income tax revenue to changes in income and tax reforms . Tax elasticity and buoyancy have been used to measure this response. To study the data the hypothesis used: Ho: Buoyancy of Personal income tax in pre and post liberalization period has remained same. The hypothesis is tested using time series data and OLS method. The paper concludes by rejecting the null hypothesis and implying that there has been a significant change in the buoyancy between the pre and post liberalization period which can be attributed to the tax reforms in the later period.

\subsection{The Effect of Tax Elasticity on Government Spending}

Eleanor and James (1980) explore the effects of tax elasticity structures on the amount of spending by state governments. The authors define tax elasticity as tax revenue generating capability of a tax structure in response to increases in tax payer's income without a change in statutory tax rates. The authors measure this for the case of US during the years 1970-1975. The authors used OLS estimation to test the hypothesis and conclude that there is significant relation between tax elasticity and government spending levels i.e, states with significantly higher tax elasticities tend to spend more than the states with correspondingly lower tax elasticities.

\subsection{Tax Elasticity in Sierra Leone: A Time Series Approach}

The authors (Brima and Festus, 2012)study the impact of the tax reforms on the tax revenues. The impact is studied by calculating the tax buoyancy and the tax elasticity for different types of taxes. To adjust the tax data for discretionary changes, Singer's dummy variable method was used. This analysis was empirically applied to data for Sierra Leone for the period from 1977 to 2009. The paper concludes by accepting the importance of discretionary measures of the government in maintaining the tax revenues during the period.

\subsection{Short- and Long-Run Tax Elasticities: The Case of the Netherlands}

'Short- and long-run tax elasticities: The case of the Netherlands'. This paper provides estimates for the base elasticities of Dutch taxes, paying particular attention to differences between short-and long-term elasticities, and allowing for asymmetric adjustment. Estimates are presented for five tax categories for the period 1970-2005, after making appropriate corrections for effects of discretionary tax measures. The empirical results indicate that shortterm elasticities often are lower than long-term ones, notably when taxes are subdued. Consequently, shocks to tax revenues tend to be aggravated by the dynamics of short-term elasticities. Ignoring differences between short- and long-term elasticities contributes to revenue 'surprises' and an incorrect assessment of the fiscal stance.

\subsection{Objective}

To find out the relationship between the tax schedule and the tax revenue for the period 1990 to 2010 , the following objectives have been formulated

1.To study the variation in buoyancy of the following taxes

- Corporation Tax 
- Income Tax

- Customs tax

- Union Excise Duty

2. To study the elasticities of the above mentioned taxes by eliminating the impact of discretionary changes.

3. To analyze the effect of tax reforms in India on the tax revenue.

\section{Methodology}

The responsiveness of tax revenue for each type is measured by its buoyancy with respect to changes in GDP. For time series analysis, tax buoyancy is estimated by using Ordinary Least Square method. The functional form measuring the tax buoyancy is

$$
\mathrm{T}=\mathrm{a} \mathrm{Y}^{\mathrm{b}}
$$

We perform a logarithmic transformation to get the equation

$\mathrm{T}=\operatorname{tax}$ revenue

$$
\log \mathrm{T}=\log \mathrm{a}+\mathrm{b} \log \mathrm{Y}+\mathrm{e}
$$

$\mathrm{Y}=$ national income

$\mathrm{a}=$ constant

$\mathrm{b}=$ buoyancy coefficient

When this equation is fitted into the data, the regression coefficient $\mathrm{b}$ gives the percentage change in tax revenue ( $\mathrm{T}$ ) corresponding with a percent change in income. If the coefficient $\mathrm{b}$ turns out to be more than one, the responsiveness of tax system will be considered relatively high and if it is less than one, the same will be considered as relatively low.

The above mentioned method assumes the existence of significant correlation between $\mathrm{T}$ (tax revenue) and $\mathrm{Y}$ (national income). An indication of this is provided by the statistic $\mathrm{R}^{2}$ that measures the goodness of fit of the functional relationship being measured. In order to obtain the buoyancy coefficient the series of gross tax receipts is regressed (inclusive of revenue yield from discretionary measures) on the income series.

Conceptually, the most appropriate measure of the responsiveness of tax revenues to changes in the base for most analytical applications is the 'elasticity', which seeks to relate the percentage change in tax revenue to a percentage change in the tax base with a given tax structure. However, since legislative changes in the tax structure alter this relationship from time to time, direct measurement of the tax elasticity from a historical revenue series often becomes problematic.

In estimating the elasticity of a tax, therefore, either the time series data on tax revenues need to be adjusted to eliminate the effects of discretionary tax measures[1], or a suitable estimation methodology has to be adopted, or a combination of the two. The most appropriate method would clearly depend upon the availability, nature and reliability of information on tax revenues, discretionary changes in the tax structure and tax bases. Over the years, at least four approaches have been used :

(1) proportional adjustment

(2) constant rate structure

(3) Divisia index

(4) econometric methods (use of dummy variables)

[1]A discretionary tax measure is a change in the tax rate or base coverage with the aim of increasing the tax revenue

The proportional adjustment method [2] has been used here to eliminate effects of discretionary tax measures. In the Indian case, estimates of tax yields arising out of discretionary changes in tax rates and coverages are routinely available in the budget documents. Therefore, the application of the proportional adjustment method is perfectly feasible for estimating tax elasticities in India. The method for calculating the adjusted tax revenue has been outlined in the Appendix I.

The adjusted tax revenue thus found was then regressed with its respective proxy base and the proxy base subsequently with GDP. The coefficients were multiplied to get the elasticity.

[2] Pronab (2009) A Note on Estimating tax Elasticities, Planning Commission Report

\section{Data and Results}

Tax revenues and their budgeted estimates were taken from the receipts budget section in the Union Budget Report of each of the years from 19990 to 2010. The proxy bases used for corporate and income tax is non agricultural GDP which was taken from the DCH databook of Centre for Statistical Organisation. The proxy tax base used for union excise duty is private consumption (also known as household consumption). Data for this has been used from the World Bank database. The customs tax is regressed with trade volume as the base and the data for this has been used from the annual reports of the Directorate General of Foreign trade. All sources of data were secondary.

The regression results were as follows: All taxes showed high $\mathrm{R}^{2}$ value when regressed with GDP implying the significance of GDP on tax revenue.

Table-5.1. Influence of Individual Taxes on GDP

\begin{tabular}{l|l}
\hline \multicolumn{2}{c}{ Table-5.1. Influence of Individual Taxes on GDP } \\
\hline Tax & R-square \\
\hline Tarporate Tax & $88.84 \%$ \\
\hline Union Excise Tax & $99.12 \%$ \\
\hline Customs Tax & $92.7 \%$ \\
Source: Based on World Bank Data & $95.4 \%$ \\
\hline
\end{tabular}

Source: Based on World Bank Data

The elasticity and buoyancy coefficients along with percentage change in tax revenues due to tax reform 
Table-5.2. Buoyancy, Elasticity and Changes in Tax Revenues due to tax Reforms

\begin{tabular}{l|l|l|l}
\hline Tax & Buoyancy & Elasticity & \% attributed to tax reforms \\
\hline Corporate tax & 2.18 & 3.24 & -48.43 \\
\hline Taxes on Income & 1.40 & 0.65 & 53.22 \\
\hline Customs tax & 0.753 & 0.30 & 60.00 \\
\hline Union Excise tax & 0.75 & 0.24 & 68.29 \\
\hline
\end{tabular}

Thus the results imply that the indirect taxes customs and union excise duties are better affected due to the tax reforms. The tax reforms have positively affected the revenues. Moreover the taxes on income attribute most of their growth in tax revenue to the growth in the tax base and hence are more elastic than the indirect taxes. The tax reforms in the corporate sector seem to have negatively affected the tax revenues and the buoyancy coefficient shows that its automatic growth is really high as compared to the others. This can be due to the instability in the tax reforms in the corporate sector. In 1997-98 company tax rate was brought down to $35 \%$ and the $10 \%$ dividend tax rate was shifted from the individual to the company. In 2001 dividend tax rate was increased to $20 \%$ and in the subsequent year it was again reduced to $10 \%$ and the individuals were taxable for the dividends instead of the company. In 2003-04 there was a reversal of policy again. Due to these continuous fluctuations and instability the reforms have adversely affected the tax revenues.

\section{Conclusion}

The tax buoyancy and elasticity were calculated and analyzed for four main types of taxes namely the corporation tax, income tax, union excise duties and custom duties for the time period 1990 to 2010 . Out of the four, the two direct taxes namely the corporation and the income tax were observed to be highly elastic. This is supposed to work in the favor of a growing economy like India as the revenue from these taxes will rapidly increase along with the increase in the respective tax bases resulting from changes in the GDP without changing the tax rates by much. The difference between the tax buoyancy and elasticity for the two direct taxes and for customs duties were found to be marginal indicating that the increase in tax revenue has been mainly due to increase in GDP. For the remaining two indirect taxes, the elasticity was observed to be lower than the direct taxes. Moreover the tax reforms seem to have had a positive effect on the tax revenues and have affected indirect tax revenue more than the direct tax revenue.

\section{Appendix}

\section{Appendix-1.}

The data cleaning process may be described in the following manner: Let :

$\mathrm{AT}_{\mathrm{i}}=$ the adjusted or cleaned tax yield in year $\mathrm{i}$

$\mathrm{T}_{\mathrm{i}}=$ the actual tax yield in year $\mathrm{i}$

$D_{i}=$ budget estimate of the yield arising out of discretionary tax changes in year $\mathrm{i}$

In the reference year ' 0 ', i.e. the year whose tax structure is to be used as the basis for building up the adjusted series, the adjusted tax yield is set at the actual:

For the following year :

$$
\mathrm{AT}_{0}=\mathrm{T}_{0}
$$

$\mathrm{AT}_{1}=\mathrm{T}_{1}-\mathrm{D}_{1}$

Since $\mathrm{AT}_{0}$ is equal to $\mathrm{T}_{0}$ by equation (1), no further adjustment is needed. In every subsequent year, however, the non-discretionary component of tax receipts have to be adjusted in the following manner:

$$
\mathrm{AT}_{\mathrm{j}}=\left(\mathrm{T}_{\mathrm{j}}-\mathrm{D}_{\mathrm{j}}\right) \frac{\mathrm{AT}_{\mathrm{j}-1}}{\mathrm{~T}_{\mathrm{j}-1}} \forall \mathrm{j}=2, \ldots \ldots ., \mathrm{n}
$$

Through sequential substitution it can be shown that equation (3) can be rewritten as :

$$
\mathrm{AT}_{\mathrm{j}}=\mathrm{AT}_{1} \cdot \prod_{\mathrm{i}=2}^{\mathrm{j}} \frac{\left(\mathrm{T}_{\mathrm{i}}-\mathrm{D}_{\mathrm{i}}\right)}{\mathrm{T}_{\mathrm{i}-1}} \forall \mathrm{j}=2, \ldots \ldots ., \mathrm{n}
$$

which is in essence the Mansfield equation for proportional adjustment data cleaning.

Appendix 2

Data tables used for regression analysis 
Table-6.1. Union Excise Taxes

\begin{tabular}{l|l|l|l|l}
\hline Year & GDP & Pvt consumption & union excise duty & Adjusted tax (AT) \\
\hline $1990-91$ & 515,032 & 339226.4362 & 23588.4656 & 23588 \\
\hline $1991-92$ & 594,168 & 386335.6105 & 27094.0608 & 21081 \\
\hline $1992-93$ & 681,517 & 457530.9015 & 29782.2929 & 18288.25273 \\
\hline $1993-94$ & 792,150 & 523893.4333 & 30973.065 & 15009.04756 \\
\hline $1994-95$ & 925,239 & 592420.8519 & 35899.2732 & 14061.91939 \\
\hline $1995-96$ & $1,083,289$ & 739072.9268 & 38890.0751 & 12102.17185 \\
\hline $1996-97$ & $1,260,710$ & 820886.8664 & 44376.992 & 11375.2055 \\
\hline $1997-98$ & $1,401,934$ & 919719.1474 & 47245.1758 & 9433.076532 \\
\hline $1998-99$ & $1,616,082$ & 1015310.643 & 53200 & 8492.632391 \\
\hline $1999-00$ & $1,786,526$ & 1156852.866 & 68526.13 & 11023.22293 \\
\hline $2000-01$ & $1,925,016$ & 1220725.272 & 91433 & 16270.50742 \\
\hline $2001-02$ & $2,097,726$ & 1354622.042 & 82309.52 & 13023.45988 \\
\hline $2002-03$ & $2,261,415$ & 1445846.659 & 90774.31 & 13410.81157 \\
\hline $2003-04$ & $2,538,170$ & 1481432.788 & 99125.43 & 13156.34032 \\
\hline $2004-05$ & $2,971,464$ & 1711301.961 & 111225.56 & 13394.27361 \\
\hline $2005-06$ & $3,390,276$ & 1931135.79 & 117612.76 & 13996.39089 \\
\hline $2006-07$ & $3,953,276$ & 2201706.966 & 123611.03 & 13923.71514 \\
\hline $2008-09$ & $4,582,086$ & 2685660.144 & 108612.78 & 8938.268029 \\
\hline $2009-10$ & $6,303,567$ & 3036922.621 & 103621 & 8292.436469 \\
\hline Source: Union Budget Reports and World Bank Database & 138299 & 11571.68652 \\
\hline
\end{tabular}

Table-6.2.Taxes on Income

\begin{tabular}{l|l|l|l}
\hline Tear & base- non agriculturalgdp & taxes on income & AT (adjusted tax) \\
\hline $1990-91$ & 364232 & 5150.32 & 5150.32 \\
\hline $1991-92$ & 418002 & 6476.431 & 4197.86 \\
\hline $1992-93$ & 483948 & 7632.99 & 2997.798 \\
\hline $1993-94$ & 562978 & 8951.295 & 2233.757 \\
\hline $1994-95$ & 661344 & 11102.87 & 2172.479 \\
\hline $1995-96$ & 796343 & 15057.72 & 2401.326 \\
\hline $1996-97$ & 915690 & 18028.15 & 2289.469 \\
\hline $1997-98$ & 1035809 & 28459.26 & 4570.329 \\
\hline $1998-99$ & 1195596 & 29367.35 & 5110.79 \\
\hline $1999-00$ & 1340011 & 31764 & 5746.105 \\
\hline $2000-01$ & 1475451 & 34438 & 5115.129 \\
\hline $2001-02$ & 1611109 & 36866 & 4635.361 \\
\hline $2002-03$ & 1789355 & 41387 & 4866.344 \\
\hline $2003-04$ & 2005828 & 49268 & 5597.795 \\
\hline $2004-05$ & 2406038 & 60757 & 6280.269 \\
\hline $2005-06$ & 2752504 & 80409 & 8621.746 \\
\hline $2006-07$ & 3230292 & 111821 & 13388.73 \\
\hline $2007-08$ & 3745568 & 106075 & 8840.653 \\
\hline $2008-09$ & 4360363 & 132314 & 12649.71 \\
\hline $2009-10$ & 5012120 & 146586 & 15784.75 \\
\hline Source: Union Budget Reports of each year and Economic Surveys & \\
\hline
\end{tabular}

Table-6.3. Customs Tax revenue

\begin{tabular}{l|c|l|l}
\hline year & Trade Volume (Tax Base) & customs tax revenue & AT(adjusted tax) \\
\hline $1990-91$ & 77,751 & 19828.732 & 19828.73 \\
\hline $1991-92$ & 91,893 & 21449.4648 & 19309.93 \\
\hline $1992-93$ & 117,063 & 22967.1229 & 18019.67093 \\
\hline $1993-94$ & 142,852 & 21704.91 & 14559.41135 \\
\hline $1994-95$ & 172,645 & 25721.6442 & 14719.31292 \\
\hline $1995-96$ & 229,031 & 34665.248 & 14246.54634 \\
\hline $1996-97$ & 257,737 & 42359.856 & 13220.94371 \\
\hline $1997-98$ & 284,277 & 40656.086 & 10350.87681 \\
\hline $1998-99$ & 318,085 & 44342.78 & 9755.242856 \\
\hline $1999-00$ & 374,797 & 47542.2 & 8818.415461 \\
\hline $2000-01$ & 434,444 & 45193 & 6596.626312 \\
\hline $2001-02$ & 454,218 & 44851.62 & 6496.966795 \\
\hline $2002-03$ & 552,343 & 48629.22 & 6939.761459 \\
\hline $2003-04$ & 652,475 & 57610.9 & 8701.141983 \\
\hline $2004-05$ & 852,411 & 65067.14 & 11622.32692 \\
\hline $2005-06$ & $1,116,827$ & 86327.24 & 17074.0648 \\
\hline $2006-07$ & $1,412,285$ & 104118.94 & 21650.89115 \\
\hline $2007-08$ & $1,668,176$ & 99878.86 & 16807.62566 \\
\hline $2008-09$ & $2,215,191$ & 83323 & 11551.75651 \\
\hline $2009-10$ & $2,209,270$ & 135812 & 21714.08028 \\
\hline
\end{tabular}

Source: Union Budget Reports and Annual Report of Directorate General Of Foreign Trade 
Table-6.4. Corporate Tax Revenue

\begin{tabular}{l|l|l}
\hline & Table-6.4. Corporate Tax Revenue \\
\hline year & corporate tax revenue & AT (Adjusted tax) \\
\hline $1990-91$ & 5150.32 & 5150.32 \\
\hline $1991-92$ & 7545.934 & 8070.8672 \\
\hline $1992-93$ & 1771.944 & 1798.889129 \\
\hline $1993-94$ & 1901.16 & 1733.282226 \\
\hline $1994-95$ & 3978.528 & -6876.881382 \\
\hline $1996-97$ & 5091.458 & 16277.41979 \\
\hline $1997-98$ & 5673.195 & -33612.06817 \\
\hline $1998-99$ & 7149.863 & 72579.38743 \\
\hline $1999-00$ & 29915 & 294180.5361 \\
\hline $2000-01$ & 35696 & 357486.5353 \\
\hline $2001-02$ & 39059 & 339677.7396 \\
\hline $2002-03$ & 46172 & 380287.9227 \\
\hline $2003-04$ & 63562 & 622868.3827 \\
\hline $2004-05$ & 82680 & 753799.1511 \\
\hline $2005-06$ & 101277 & 838603.9922 \\
\hline $2006-07$ & 144318 & 1288632.937 \\
\hline $2007-08$ & 213395 & 1941371.559 \\
\hline $2008-09$ & 244725 & 2017040.042 \\
\hline $2009-10$ & 298687 & 2199745.43 \\
\hline Source: Union Budget Reports (Receipt Budgets) & 2661024.563 \\
\hline
\end{tabular}

\section{References}

Ankita, G., 2009. The trends and responsiveness of personal income tax in India. Fourth Annual International Conference on Public Policy and Management, IGIDR Proceedings-Project Reports Series. pp: 062-29.

Brima, I.B.K. and E.O. Festus, 2012. Tax elasticity in sierra leone: A time series approach. International Journal of Economics and Financial Issues, 2(4): 432-447. View at Google Scholar

Eleanor, C.D. and H.A. James, 1980. The effect of tax elasticity on government spending. Journal of Public Choice, 35(3): 267-275. View at Google Scholar

Fauzia, M., 2001. Elasticity and buoyancy of major taxes in Pakistan. Pakistan Economic and Social Review, 39(1): 75-86. View at Google Scholar Pronab, S., 2009. A note on estimating tax elasticities. Planning Commission Reports, Working Paper Series.

\section{Bibliography}

Guido, W., 2007. Short- and long-run tax elasticities: The case of the Netherlands. European Central Bank, No. 273. 